\title{
Magnetic Resonance Imaging: Historical Overview, Technical Developments, and Clinical Applications
}

\author{
Geon-Ho Jahng ${ }^{1(\mathbb{1})}$, Soonchan Park ${ }^{1(i)}$, Chang-Woo Ryu ${ }^{1(i)}$, Zang-Hee Cho $^{2(\mathbb{D}}$ \\ ${ }^{1}$ Department of Radiology, Kyung Hee University Hospital at Gangdong, College of Medicine, Kyung Hee University, ${ }^{2}$ Neuroscience \\ Convergence Center, Korea University, Seoul, Korea
}

Received 29 May 2020

Revised 1 August 2020

Accepted 1 September 2020

Corresponding author

Geon-Ho Jahng

(ghjahng@gmail.com)

Tel: 82-2-440-6187

Fax: 82-2-440-6932
The authors congratulate the cerebrations for the 30 years of the Korean Society of Medical Physics (http://www.ksmp.or.kr/). The paper is published to recognize the anniversary. Geon-Ho Jahng invited Professor Z. H. Cho to join to submit this manuscript because he has been one of the leaders in the field of magnetic resonance imaging (MRI) during the last 40 years. In this review, we describe the development and clinical histories of MRI internationally and domestically. We also discuss diffusion and perfusion MRI, molecular imaging using MRI and MR spectroscopy (MRS), and the hybrid systems, such as positron emission tomography-MRI (PET-MRI), MR-guided focused ultrasound surgery (MRgFUS), and MRI-guided linear accelerators (MRI-LINACs). In each part, we discuss the historical evolution of the developments, technical developments, and clinical applications.

Keywords: Magnetic resonance imaging, History, Technical development, Clinical application, Review

\section{History of Magnetic Resonance Imaging}

\section{International contributions}

The first nuclear magnetic resonance (NMR) signals from a living animal were acquired from an anesthetized rat in 1968 [1]. The capability of NMR to differentiate tumors from normal tissue was reported by Damadian in 1971 [2]. Magnetic resonance imaging (MRI) was developed by Lauterbur [3] based on the encoding spatial information of NMR signals with magnetic field gradients. The first crosssectional image of a living mouse was published in 1974 by Lauterbur [4]. The echo-planar imaging (EPI) technique was developed by Mansfield [5]. The first MRI body scan of a human being was performed by Damadian in 1977 [6]. For their efforts, Paul C. Lauterbur and Peter Mansfield were awarded the Nobel Prize in Physiology and Medicine in 2003 in justification of the fundamental importance and applicability of MRI in medicine. The k-space was patented by Richard S. Likes in U.S.A (\#U.S. Patent 4,307,343). The first clinical MRI system was installed in the early 1980s. The first whole-body MRI scanner was developed in Korea in 1982 and was commercialized in 1984 by Goldstar (Seoul, Korea). At same time, another whole-body MRI system was built at the University of Aberdeen and was used at St. Bartholomew's Hospital (London, UK) in 1983. Superconducting MRI was developed and it was clinically used in 1985 to 1988 at Siemens (Erlangen, Germany), General Electric (GE, Boston, MA, USA), and Goldstar. Fig. 1 shows the timeline of MRI developments and a summary of the major contributions achieved internationally and domestically. 


\section{Timeline of MRI}

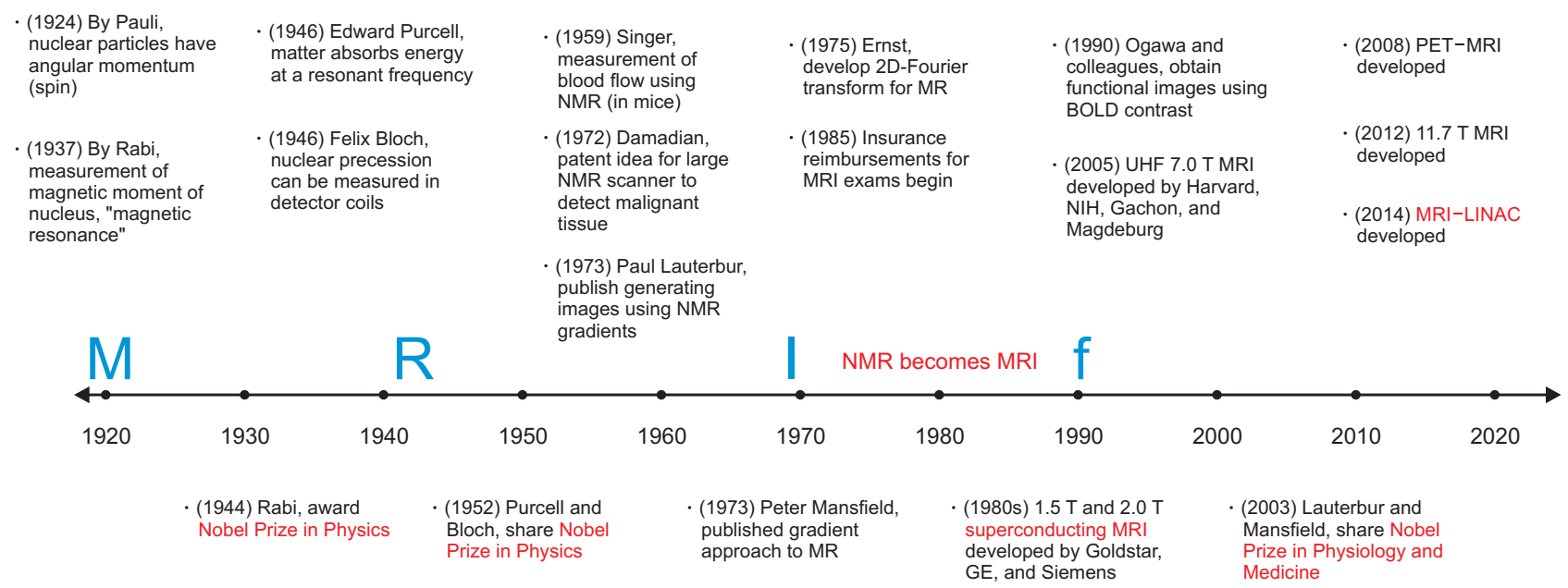

Fig. 1. Timeline of MRI developments and summary of the major contributions. MRI, magnetic resonance imaging; M, magnetic; R, resonance; I, imaging; F, functional; NMR, nuclear magnetic resonance; BOLD, blood oxygen level-dependent; NIH, National Institutes of Health; PET, positron emission tomography; MRI-LINAC, MRI-guided linear accelerators.

\section{Domestic contributions}

The first MRI system was developed by the Korean Advanced Institute of Science and Technology (Daejeon, Korea), and was installed in Shin Hwa Hospital (Shin Hwa Nursing Hospital, Seoul, Korea) in 1984. This MRI scanner used a $0.2 \mathrm{~T}$ permanent magnet. Therefore, its use for clinical studies was limited considerably at that time. The first commercial MRI (Spectro-20000; Goldstar) was installed in Seoul University Hospital (Seoul, Korea) in 1987. This MRI system was a 2.0 Tesla superconductivity magnet. During this period, GE, and Siemens also developed the $1.5 \mathrm{~T}$ superconductive MRI systems. In 1990, the first animal 4.7 T MRI system (Biospec, Bruker, Switzerland) was installed in Seoul's Asan Joong Ang Hospital (Asan Medical Center, Seoul, Korea). Among the many incremental developments in MRI in Korea, one of the notable progresses made during the early 21st century was the development of ultrahigh field (UHF) 7.0 T MRI and its applications [7-11]. Another notable worldwide research activity was the development of the hybrid positron emission tomography-MRI (PETMRI) system. Since the introduction of the UHF (7.0 T) MRI system in Korea, an effort was initiated for the construction of a hybrid system with 7.0 T MRI and PET that led to the development of one of the world's most advanced PET-MRI systems in 2007. With these developments, a number of neurotransmitter studies was initiated to study the serotonergic distribution in the brainstem in vivo $[7,8]$. Another new and interesting development with UHF 7.0 T MRI was the super-resolution tractography initiative with resolution down to $200 \mu \mathrm{m}$ [12].

\section{Development of basic imaging contrast}

In 1950, spin echoes and free induction decay were detected by Hahn $[13,14]$. Therefore, the spin echo (SE) is commonly referred to as Hahn's echo. MR angiography was developed by Charles L. Dumoulin and Howard R. Hart at the General Electric in 1986 ("Blood-flow checker". Popular Science: 12. 1987). The fluid attenuation inversion recovery (FLAIR) pulse sequence that yields high-signal regions in normal white matter, was demonstrated by Hajnal et al. in 1992 [15]. Blood Oxygen Level Dependent signal was recognized by Ogawa [16] at AT\&T Bell labs in 1990. Susceptibility-weighted imaging (SWI) was developed by Reichenbach et al. [17] at Washington University in 1997.

Fig. 2 shows patient cases that demonstrate the use of imaging contrast agents acquired from a 83-year-old female, 71-year-old male, and from a 26 -year-old male with a $3 \mathrm{~T}$ MRI system. 
a

83/F

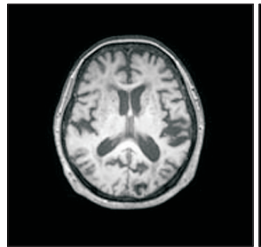

T1W

b

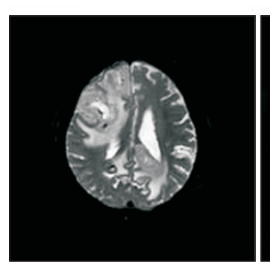

71/M

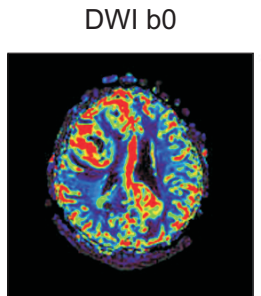

DSC rCBV

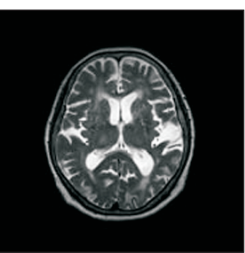

T2W

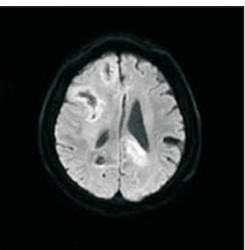

DWI b1,000

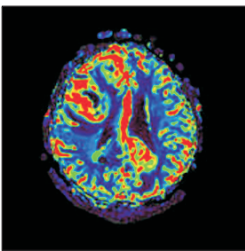

DSC rCBF

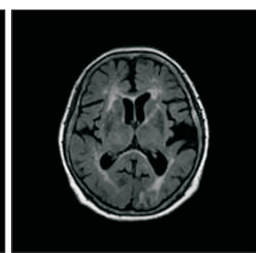

Flair

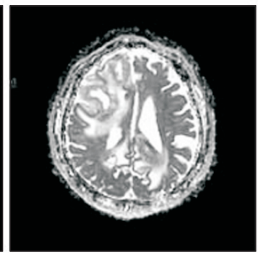

ADC

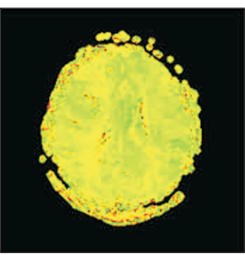

DSC MTT

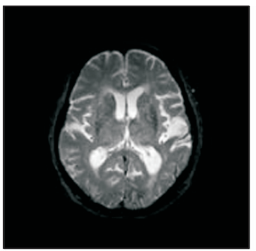

GRE

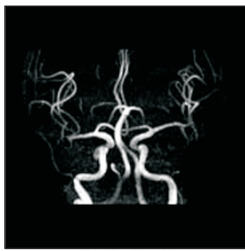

TOF

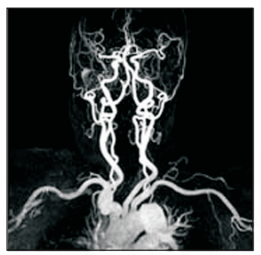

CE MRA

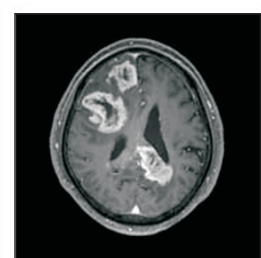

CE T1W

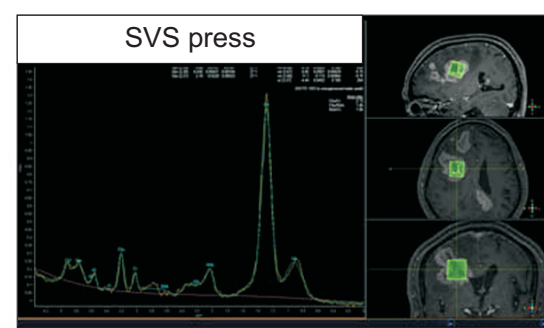

C

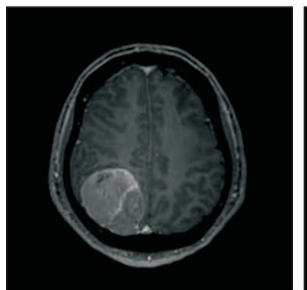

CE T1W

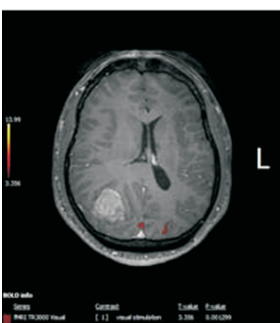

fMRI visual

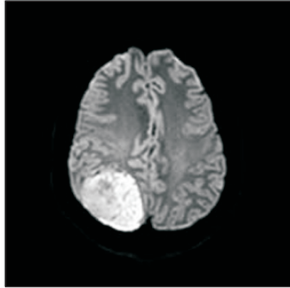

DTI b1,000

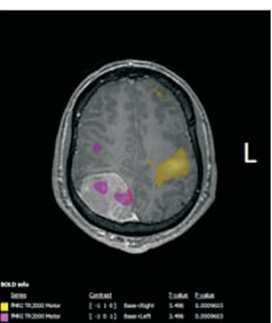

fMRI visual

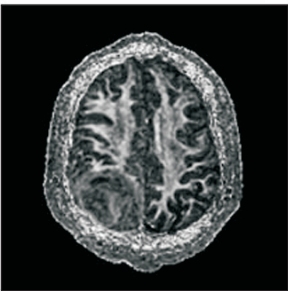

DTI FA

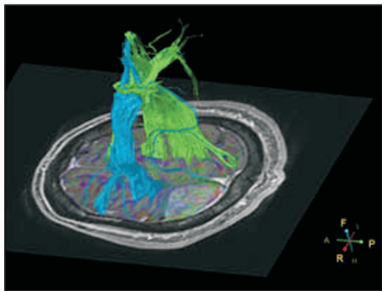

DTI motor fibers

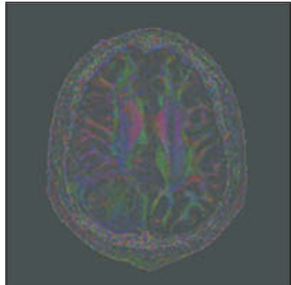

DTI colorcode

Fig. 2. Patient cases to show imaging contrasts acquired from (a) 83-year-old female, (b) 71-year-old male, and (c) 26-year-old male using a 3 T MRI system. F, female; M, male; T1W, T1-weighted; T2W, T2-weighted; FLAIR, fluid attenuated inversion recovery; GRE, gradient-echo; TOF, time of flight; CE MRA, contrast-enhanced magnetic resonance angiography; DWI b0, diffusion-weighted image with $b=0 \mathrm{~s} / \mathrm{mm}^{2}$; DWI b1000, diffusion-weighted image with $\mathrm{b}=1000 \mathrm{~s} / \mathrm{mm}^{2}$; ADC, apparent diffusion coefficient; CE T1W, contrast-enhanced T1-weighted; APT, amide proton transfer; DSC rCBV, dynamic susceptibility contrast relative cerebral blood volume; DSC rCBF, dynamic susceptibility contrast relative cerebral blood flow; DSC MTT, dynamic susceptibility contrast mean transit time; SVS, single voxel spectroscopy; DTI b1000, diffusion tensor imaging with $\mathrm{b}=1000 \mathrm{~s} / \mathrm{mm}^{2}$; DTI FA, diffusion tensor imaging fractional anisotropy; fMRI, functional MRI.

\section{Fast Imaging Techniques}

Speed is always important to clinical practice. Fast MRI techniques were introduced and were based on the use of multiple refocusing pulses, commonly referred to as turbo spin-echo (TSE) imaging or turbo gradient-echo imaging. 
Rapid Acquisition with Refocused Echoes (RARE) technique was commercially implemented after Hennig [18] described it in 1986. In this sequence, the echo train length (ETL), also known as the turbo factor, denotes the number of echoes acquired at a given repetition time (TR). Spiral sequences were introduced in 1986 by Ahn et al. [19].

\section{Technical developments}

Several pulse sequences for fast imaging were developed, such as TSE or turbo field echo, half-Fourier, single-shot turbo spin echo (HASTE), gradient and spin echo (GRASE), balanced steady-state free-precession (bSSFP), EPI, and spiral [20]. First, the principle of operation of TSE or RARE sequences was based on the filling of many k-space lines after every radiofrequency (RF) excitation that reduced the MR scan time by reducing the number of RF excitations required for each image [21]. Second, HASTE was a singleshot version of the TSE technique [22] wherein slightly more than half the total number of required phase encoding lines of the k-space were acquired after a single RF excitation. Third, turbo gradient spin echo or GRASE, is a turbo SE sequence with additional phase encoding gradient echoes between successive $180^{\circ}$ refocusing pulses [23]. Fourth, bSSFP is a gradient-echo sequence that accomplishes fast acquisitions by eliminating idle times [24]. In the most common case, the data are mapped line-by-line from the top to bottom parts of k-space in a lexicographic manner, commonly referred to as Cartesian sampling. Fifth, EPI allows the collection of all the data required to reconstruct an image after a single RF excitation [25] and spiral imaging acquires data using two oscillating gradients that create a spiral trajectory in k-space [19]. The single-shot approach of EPI or spiral is the fastest with a subsecond acquisition time. Therefore, these techniques are usually used in functional MRI (fMRI). Furthermore, radial trajectories have also been introduced [26].

Several reconstruction methods were also developed to achieve higher signal-to-noise ratios (SNR) and reduced scan times. Parallel imaging techniques in conjunction with the use of phased array coils have been developed to reduce scan times by acquiring a reduced amount of k-space data with an array of receiver coils. These techniques include the simultaneous acquisition of spatial harmonics (SMASH) [27], sensitivity encoding (SENSE) [28], and generalized auto-calibrating partially parallel acquisitions (GRAPPA) [29]. SENSE is based on reconstruction in the imaging domain, but GRAPPA is based on k-space domain reconstruction. These parallel imaging techniques are being further developed nowadays [30]. Recently, multiband excitation imaging and finger printing imaging techniques have been developed to reduce the scan times even further.

The simultaneous multislice (SMS) pulse sequence [31] applies a multiband composite RF pulse with a slice-selective gradient to simultaneously excite multiple slice planes [32]. The multiband technique is simultaneous image refocused (SIR) EPI or simultaneous echo refocused (SER) EPI that does not use parallel imaging and coil sensitivity for image separation [33]. Another recently developed fast imaging technique is magnetic resonance fingerprinting (MRF) [34]. This technique allows simultaneous and efficient measurements of multiple tissue properties with one acquisition [35]. In MRF, the acquisition parameters, such as the RF excitation angle, phase, repetition time, and k-space sampling trajectory, are varied throughout the acquisition. When implemented properly, this acquisition could generate a unique signal time course for each tissue. For every MRF sequence, the dictionary of signal evolutions can be generated on a computer using mathematical algorithms to predict spin behavior and signal evolution during the acquisition.

\section{Clinical applications}

Ultrafast imaging is used to eliminate the effects of physiological motion, thus capturing dynamic events in real time or shortening the total scan time. Shortening the scan time helps improve patient comfort and compliance, thereby minimizing motion during scans [36]. At higher imaging speeds, it becomes feasible to examine a wide range of relevant physiological processes or to freeze induced motion that may otherwise lead to artifacts. Relevant physiological processes include, among others, respiration [37], cardiac rhythm [38], and hemodynamics from neuronal activation [39]. For example, ultrafast imaging is often used in cardiovascular imaging $[40,41]$. 
SENSE or GRAPPA are commonly used in the clinical practice nowadays. Multiband technique is used in fMRI. However, there is always an inherent trade-off between imaging speed and quality. MRF was initially evaluated in brain relaxometry [35], prostate [42], liver [43], cardiac [44], musculoskeletal imaging [43], arterial spin labeling (ASL) perfusion measurement [45], and microvascular properties [46].

\section{Diffusion MRI}

A diffusion process is described by Fick's law. Einstein described the relationship between the mean-squared displacement and diffusion coefficient in Brownian motion [47]. Diffusion is dependent on concentration, pressure, and temperature (https://en.wikipedia.org/wiki/Diffusion). Diffusion MRI is currently a well-established technique that is used in routine clinical practice to identify lesions and to characterize them. Diffusion MRI was developed by Le Bihan in 1989 [48]. Diffusion tensor imaging (DTI) and fiber tractography were developed by Peter Basser and Le Bihan in the early 1990s [49-51]. The diffusion coefficient for water at $37^{\circ} \mathrm{C}$ is approximately $D=3 \times 10^{-9} \mathrm{~m}^{2} / \mathrm{s}$.

\section{Technical developments}

Diffusion-weighted imaging (DWI) was developed to investigate microstructural properties by evaluating the proton diffusion process. The technique is used to characterize the microscopic behaviors of protons noninvasively. The diffusion coefficient or apparent diffusion coefficient (ADC) is measured on the basis of the use of diffusion gradients around the refocusing pulse in the SE sequence, or the use of bipolar gradients in the gradient-echo sequence within the echo time (TE) time period, and is fitted by the monoexponential decay curve [50].

$$
S=S_{0} e^{-b D}
$$

where $b$ is the b-factor that can be calculated using the strength of the applied diffusion gradient, the duration of the diffusion gradient, and the duration of the period between two diffusion gradients.

A two-compartment model was applied to measure diffu- sion from intracellular and extracellular compartments, respectively referred to as slow $\left(D_{\text {slow }}\right)$ and fast $\left(D_{\text {fast }}\right)$ diffusion with the corresponding volume fractions $\mathrm{F}_{\text {slow }}$ and $\mathrm{F}_{\text {fast }}[52]$.

$$
S=S_{0}\left[F_{\text {fast }} e^{-b D_{\text {fast }}}+F_{\text {slow }} e^{-b D_{\text {slow }}}\right]
$$

The intravoxel incoherent motion (IVIM) method was introduced to separate diffusion from flow effects in a voxel [50]. In this technique, the flowing vascular volume fraction of incoherently flowing blood in the tissue (F), pseudodiffusion coefficient ( $\left.D^{*}\right)$ associated to the IVIM effect, and true diffusion coefficient (D) can be measured by applying multiple b-values.

$$
S=S_{0}\left[F_{\text {flow }} e^{-b D^{*}}+\left(1-F_{\text {flow }}\right) e^{-b D}\right]
$$

Because in vivo proton movement is not isotropic, anisotropic diffusion was introduced by assuming ellipsoidal diffusion, known as DTI [51]. The diffusion coefficient in the DTI model is a $3 \times 3$ symmetric matrix. Eigenvalues and eigenvectors can be extracted from the tensor matrix to calculate the isotropic diffusion effects by using the mean diffusivity $\left(\mathrm{MD}=\left(\mathrm{D}_{\mathrm{xx}}+\mathrm{D}_{\mathrm{yy}}+\mathrm{D}_{\mathrm{zz}}\right) / 3\right)$, and anisotropic diffusion effects by using fractional anisotropy (FA) index that represents the variance of the three eigenvalues divided by norm of the eigenvalues.

Tensor models can be applied by assuming Gaussian distributions of proton movements. However, in biological structures, water molecular diffusion is hindered in the extra-axonal space and restricted in the intra-axonal space [53]. To take this effect into account, other models were introduced, such as the ball-and-stick model [54], Q-ball imaging (QBI) [55], diffusion spectrum imaging (DSI) [56], spherical deconvolution model [57], and neurite orientation dispersion and density imaging (NODDI) [58]. Furthermore, non-Gaussian diffusion kurtosis imaging, was applied in clinical studies [59].

Finally, tractography techniques were introduced to detect white matter fiber bundles by measuring the eigenvectors along the fibers $[60,61]$. Improvements of fiber tracking were further achieved by using probabilistic models [62]. Tractography is currently used to investigate white matter connectivity in healthy brains and in several pathologic 
conditions [63].

\section{Clinical applications}

Diffusion MRI techniques, including DWI, DTI, and tractography, are currently extensively used in clinical settings. DWI is routinely applied in stroke and tumor patients. Diffusion indices of MD and FA are altered in the presence of ischemic injury [64] and in neoplasms [65]. In brain neoplasms, ADC values have been shown to be decreased in highly cellular tumors, such as central nervous system (CNS) lymphoma, medulloblastoma, and high-grade glioma [66]. Diffusion imaging techniques were applied in Alzheimer's disease [67-71]. Furthermore, malignant lesions have lower ADC values compared with surrounding normal tissue, edema, and benign tumors in the brain, head and neck malignancies, prostate, and liver cancer [72]. Diffusion-weighted whole-body imaging with background suppression (DWIBS) was performed with the short tau inversion recovery (STIR) EPI sequence with a high $b$ value for background suppression to evaluate metastatic lesions in the body [73]. DTI was used to evaluate dislocation, disruption, infiltration, and edema. Tractography was used to evaluate corticospinal tract fibers, optic radiation fibers, and language fibers in patients to perform presurgical planning in neoplastic brain tumor cases.

\section{Perfusion MRI}

Perfusion refers to the delivery of blood to a capillary bed in tissue. This is different compared with bulk flow motion (https://en.wikipedia.org/wiki/Perfusion). August Krogh first described the mechanism of regulation of capillaries in muscle, and was awarded the Nobel Prize in Physiology or Medicine [74]. Perfusion MRI is categorized according to the use of a contrast agent or not. Dynamic-susceptibilitycontrast (DSC)-based perfusion MRI was developed by Villringer et al. in 1988 [75]. The ASL technique was developed by Koretsky in 2012 [76].

\section{Technical developments}

Details of perfusion MRI were summarized in a previous paper [77]. Three important techniques are currently used in clinical practice to obtain perfusion-related parameters. The first-pass DSC-enhanced MR perfusion is based on the susceptibility effects of gadolinium-based contrast agents on the signal echo. Therefore, T2- or T2*-weighted imaging sequence, usually a gradient-echo or an EPI sequence, is used to obtain the signal attenuation of the time-series images. Cerebral blood volume (CBV) and flow (CBF) values as well as time-related parameters, such as the mean transit time (MTT) and time-to-peak can be mapped in each pixel. Convolution theory is used to evaluate the measured concentrations of the hemodynamic changes of the contrast agent as follows [78],

$$
C(t)=C B F \cdot \int_{0}^{t} C_{a}\left(t^{\prime}\right) \cdot R\left(t-t^{\prime}\right) d t^{\prime}
$$

where $\mathrm{C}_{\mathrm{a}}(\mathrm{t})$ is the measured arterial input function (AIF) that describes the shape of the tracer that enters a voxel, and $\mathrm{R}\left(\mathrm{t}-\mathrm{t}^{\prime}\right)$ is the unknown residue function that describes the probability of the tracer entering a voxel. Therefore,

$$
\mathrm{MTT}=\int_{0}^{\infty} R(t) d t, \mathrm{CBV}=\int_{0}^{\infty} C_{T}(t) d t / \int_{0}^{\infty} C_{a}(t) d t
$$

, and $\mathrm{CBF}=\mathrm{CBV} / \mathrm{MTT}$.

The dynamic contrast-enhanced (DCE) MR perfusion is based on the relaxivity effects of gadolinium-based contrast agents on the signal echo. Therefore, a transverse relaxation (T1)-weighted imaging sequence (usually a threedimensional sequence), is used to obtain signal increments of time-series images. The area under-the-curve can be mapped. Furthermore, a pharmacokinetic model is used to map permeability-related parameters such as $\mathrm{K}^{\text {trans }}$ and $\mathrm{K}_{\mathrm{ep}}$ and the corresponding volume fractions such as $\mathrm{v}_{\mathrm{p}}$ and $\mathrm{v}_{\mathrm{e}}$. The general equation used to express the hemodynamic event after injecting the contrast agent is expressed with the extended Tofts model as follows [79],

$C_{\text {tissue }}(t)=v_{p} C_{p}(t)+K^{\text {trans }} \int_{0}^{t} C_{p}\left(t^{\prime}\right) \exp \left(-\frac{K^{\text {trans }}}{v_{e}}\left[t-t^{\prime}\right] d t^{\prime}\right)$

where $\mathrm{C}_{\mathrm{p}}(\mathrm{t})$ is the concentration of contrast agent in blood, $\mathrm{K}^{\text {trans }}$ is the permeability-surface area constant from the vascular to the extracellular space, and $\mathrm{v}_{\mathrm{e}}$ is volume fraction in 
the extravascular and extracellular space.

The ASL MR perfusion is based on an endogenous contrast agent using magnetically labeled arterial blood water as a diffusible flow tracer. Therefore, the proton-densityweighted sequence is used to obtain signal changes with and without the use of magnetically labeled blood by either continuous or pulsed RF pulses. $\mathrm{CBF}$ value can be quantified. A general kinetic model for the evaluation of the difference of the longitudinal magnetization in the tissue owing to the labeled blood can be expressed to quantify the blood flow as follows [80],

$$
\Delta \mathrm{M}(t)=2 M_{0 b} \cdot C B F \cdot \int_{0}^{t}\left[C_{a}\left(t^{\prime}\right) \cdot R\left(t-t^{\prime}\right) \cdot m\left(t-t^{\prime}\right)\right] d t^{\prime}
$$

where $\mathrm{M}_{0 \mathrm{~b}}$ is the equilibrium magnetization in a blood filled arterial voxel, $\mathrm{C}_{\mathrm{a}}(\mathrm{t})$ is the delivery function, such as AIF, $R\left(t-t^{\prime}\right)$ is the residue function that describes the washout of tagged spins from a voxel, and $\mathrm{m}\left(\mathrm{t}-\mathrm{t}^{\prime}\right)$ includes the longitudinal magnetization relaxation effects. The pseudocontinuous ASL (pCASL) technique was introduced to improve the ASL signals [81], and is currently used in clinical practice.

\section{Clinical applications}

Perfusion MRI is a promising tool used to assess stroke, tumors, and neurodegenerative diseases. DSC perfusion MRI is the standard technique used to evaluate brain diseases, such as stroke [82] and tumors [83]. A combination of perfusion and DWI is used to evaluate a mismatch between the size of a perfusion defect and the diffusion abnormality that is referred to as the ischemic penumbra [84]. Tumor grade, recurrence, postoperative changes, or radiation effects can be established with DSC perfusion imaging [85].

DCE perfusion MRI is often applied in brain diseases [86] and in patients with breast, prostate, pelvic, and muscle diseases, and can be useful in differentiating between tumor recurrence and radiation necrosis. The DCE parameters reflect a more extensive $\mathrm{BBB}$ disruption and a higher tumor grade [87], evaluate the treatment prediction [88], and differentiate pseudo-progression from true progressive disease in GBM patients [89].

ASL perfusion MRI is mainly applied in brain diseases, such as neurodegenerative [90,91], renal, and cardiovascular diseases. ASL perfusion MRI has been used to evaluate pseudo-progression in brain tumor [92]. This method is particularly useful for patients with poor intravenous access, infants and children, and pregnant women [93].

\section{Molecular MRI/MR Spectroscopy}

MR spectroscopy (MRS) is used to determine the molecular structure of compounds, or to detect their presence. Proton MRS is based on the proton's magnetic moment and its interaction with magnetic fields. MRS is thus sensitive to certain aspects of tissue metabolism. Proton MRS can detect N-acetyl aspartate (NAA), creatine/phosphocreatine (Cr/PCr), choline (Cho), glucose (Glu), myoinositol (ml or mlns), lactate (Lac), alanine (Ala), glutamate and glutamine (GIx), citrate, and ethanol in the human body. MRS can detect other nuclei in compounds of biological interest, such as phosphorus-31 (found in PCr) or carbon-13 (found in glycogen). However, proton MRS is more routinely performed in clinical practice compared with 31P or 13C MRS. Therefore, in this review, we only discuss proton MRS.

Chemical exchange saturation transfer (CEST) is a novel MR technique that enables molecular imaging to obtain certain compounds at concentrations that are too low to impact the contrast of standard MRI and too low to be directly detected in MRS at typical water imaging resolutions.

\section{Technical developments of MRS}

\section{1) Pulse sequences}

A single voxel spectroscopy (SVS) study is performed with short or long TE values. The SVS pulse sequences are the following: point resolved spectroscopy (PRESS) [94], stimulated echo acquisition mode (STEAM) [95], image selected in vivo spectroscopy (ISIS) [96], and depth-resolved spectroscopy (DRESS) [97]. Longer TE results in the signal decrease as a result of the transverse relaxation (T2) that leads to the alteration of the phase of multiplet signals because of J-coupling [98]. TE values in the range of 135-144 ms are typically used, as this leads to the production of a spectrum in which the doublet signal of Lac with a J-coupling constant of nearly $7 \mathrm{~Hz}$ is entirely reversed owing to the short 
TE and long TR [99].

A spectroscopic imaging is an area of interest. Chemical shift imaging (CSI) is used for multiple-voxel spectroscopic acquisitions. In spectroscopic imaging, phase encoding gradients can be applied in all three dimensions to sample k-space to select a volume that resembles methods used in MRI [100].

\section{2) Water suppression methods}

The water resonance must be suppressed to detect the millimolar concentrations of other molecules/moieties. The most common suppression method is based on the use of a chemical shift selected (CHESS) pulse sequence [101].

\section{3) Spectral quantification}

The typical postprocessing techniques used include Fourier Transform (FT), baseline correction, zero filling, and phasing. Quantification of the MRS signal amplitude can provide a means for estimating the tissue concentration of the signal generating molecules. While MRS signals are usually acquired in the time domain as free induction decays or echoes, they are usually viewed and analyzed in the frequency domain. The frequency domain representation is derived from the acquired time domain data by the FT. Signal averaging is used in virtually all MRS studies to increase the SNR by averaging the signals obtained in repeated measurements. To quantify the proton spectrum in most of the clinical studies, the internal reference signal is typically used that is either the $\mathrm{Cr}$ signal at $3.05 \mathrm{ppm}$ or the water signal at $4.69 \mathrm{ppm}$. When $\mathrm{Cr}$ is used as a reference signal, it is more common to report results as signal amplitude ratios, such as NAA/Cr, or Cho/Cr. One weak aspect related to the use of the $\mathrm{Cr}$ signal as a reference is attributed to the fact that the $\mathrm{Cr}$ signal is not as uniform throughout the normal brain [102]. Another weak aspect pertains to the fact that the assumption of the Cr levels do not change with disease and other physiological characteristics may be erroneous. If the water signal is used as a reference signal, its amplitude must be measured by performing a separate measurement in the same brain region without using water suppression.

A linear least-squares optimization procedure has been established and used in spectral fitting techniques. The most popular spectral fitting software is currently the LC-
Model [103,104]. Furthermore, spectrum fitting software is available either in the time [105] or frequency domains $[106,107]$.

\section{Molecular imaging tools other than MRS}

CEST can be used to apply molecular imaging [108]. This technique is more appropriate compared with CSI or MR spectroscopy imaging because it provides relatively high resolution. The principle of CEST is based on the use of the magnetization transfer effects from other molecules to water molecules. Therefore, the requirement of CEST is that the chemical species must have in their structures a $1 \mathrm{H}$ proton that is exchangeable with those of water. Known endogenous diamagnetic CEST agents are involved with exchangeable groups of amide proton (-NH), amine proton (-NH2), and hydroxyl proton (-OH), whose chemical shifts are $\sim 3.5, \sim 1.8-3.0$, and $\sim 0.5-1.5$ parts per million (ppm), respectively [109]. Amide CEST is usually referred to as amide proton transfer (APT). CEST techniques have been applied to map glutamate (amine proton), creatine (amine proton), glycosaminoglycan (Gag) (hydroxyl proton), myoinositol (MI) (hydroxyl proton), and glucose (hydroxyl proton). The detailed principle of CEST technique has been described in numerous previous papers [110-116].

\section{Clinical applications}

The goal of clinical spectroscopy is to provide physicians with biochemical information that will assist in the differential diagnosis when standard clinical and radiologic tests fail or are too invasive. Proton spectroscopy has attained clinical value in that it can monitor the evolution of diseases and associated therapies. Disease can sometimes lead to large changes in metabolite levels.

MR spectroscopy has also been shown to be of diagnostic value for evaluating and monitoring the progression of certain brain diseases, such as stroke [117], epilepsy, multiple sclerosis [118], Alzheimer's disease [119,120], brain tumors [121] and other tumors, such as prostate cancer [122] and breast cancer [123]. Lactate signal levels are elevated in ischemic brain tissue. Choline signal levels are elevated in some neoplastic or inflamed tissues. 
The main applications for amide CEST or APT are the detection of cancer and ischemic stroke. In tumor regions, the concentration of proteins are elevated compared with surrounding tissues, and thus lead to increased APT levels [124]. This method was applied to classify tumor progression from radiation necrosis [125]. The CEST technique is applied in stroke because reduced $\mathrm{pH}$ in the ischemic region leads to lowered APT exchange rate, and results in decreased CEST values [126]. CEST was applied in otherthan-brain pathologies, such as breast [127], prostate [128], and knee [129].

\section{Hybrid MRI Systems}

\section{PET-MRI}

PET-MRI is an imaging system that incorporates MRI and PET to gain from the benefits of soft tissue morphological imaging (MRI) and metabolic imaging (PET). This hybrid system is mainly used in the fields of oncology and neurology for clinical and preclinical studies. Some systems operate in totally separate rooms, but other systems do operate in the same room with separate machines. In these cases, a bed is shared to transfer the subjects from MRI to PET or to fully integrated systems. The first whole-body PETMRI systems were produced by Philips (Amsterdam, The Netherlands) and were installed in the US (Mount Sinai Medical Center, New York, NY) and in Switzerland (Geneva University Hospital, Geneva) in 2010. The system featured a PET and MRI scanner separated by a revolving bed. The simultaneous PET-MR acquisition system (Siemens) was installed in 2010. The fully integrated whole-body systems were provided in 2011 by Siemens and in 2014 by GE. In Korea, the first PET-MRI system was installed at the Gachon University Hospital (Inchen, Korea) [7,8].

\section{1) Technical developments}

In this part, we only discussed the issues of the fully integrated PET-MRI system. Placing PET detectors in the MR magnet can alter the local magnetic field strength causing the protons to spin at wrong frequencies, thus leading to the formation of severe image distortions and artifacts, such as susceptibility artifacts. The presence of PET hardware within the gradient coil significantly alters the MR eddy current characteristics of the system possibly leading to degraded spatial linearity. The gradient imperfection would impact imaging spatial resolution and image homogeneity. The lutetium-based scintillation crystals have acceptable magnetic properties [130]. The avalanche photodiode for PET can be used in a $7 \mathrm{~T}$ MRI system without inducing major effects to magnetic fields [131].

Attenuation correction describes a method to account for the self-absorption of the emitted annihilation photons, and is a prerequisite for accurate quantification of the PET data [132]. It is not possible to directly derive the attenuation properties of tissues from MRI measurements. MRI-based attenuation correction methods have been introduced [133]: segmentation-based [134] that are usually used in T1-weighted images [135] or Dixon-sequence-based images [136], atlas-based [133], and reconstruction-based [137] methods. Attenuation correction of bone is calculated by using ultrashort echo time images [138].

The simultaneous acquisition of MRI and PET data in the fully integrated PET-MRI systems has major advantages compared with sequential acquisitions. Two-dimensional or three-dimensional (3D) navigator MRI is used to correct respiratory motion in PET images [139]. 3D Cine MRI has been used to correct cardiac motion in PET images [140]. A high resolution MRI has been used for the correction of the partial volume effect in PET images [141]. MR-guided PET reconstruction techniques have been developed by incorporating "a priori" anatomical information from the MRI [142]. Finally, MR anatomical images have been used for aligning functional information obtained from PET [143].

\section{2) Clinical applications}

While PET provides a) the high sensitivity required to detect minute amounts of radiotracers and b) the ability to quantify radiotracer activity throughout the body in absolute terms, MRI provides excellent soft-tissue contrast according to multiple contrast mechanisms at high-spatial resolution. Therefore, PET/MRI imaging combines the diagnostic breadth and information content of both PET and MRI. The PET-MRI system has been used for the study of patients with hepatobiliary cancer [144], neuroendocrine tumors [145], pancreatic adenocarcinoma [146], prostate 
cancer [147], primary brain tumors [148], dementia [149], epilepsy [150], musculoskeletal tumor [151], and coronary artery disease [152].

\section{MR-guided focused ultrasound surgery}

High-intensity focused ultrasound (HIFU) is a noninvasive therapeutic technique that uses nonionizing ultrasonic waves to heat tissue [153]. HIFU has been combined with MRI to enable guidance of the treatment and monitoring. It is referred to as MR-guided focused ultrasound surgery (MRgFUS). It is a 3D imaging technique that features highsoft-tissue contrast and provides information about temperature, thus allowing the monitoring of ablation. In 1992, reports were published that described MRgFUS on ex vivo muscle tissue [154], and the following year on in vivo tissue [155]. MRgFUS developed by Hynynen [155] was later transferred to InsighTec in Haifa, Israel in 1998. The InsighTec ExAblate 2000 was the first MRgFUS system used to obtain Food and Drug Administration market approval in the US in 2004.

\section{1) Technical developments}

In MRgFUS, MR is used for both target localization and in vivo real time monitoring of temperature based on a technique referred to as MR thermometry [155], and for verifying tissue destruction using a postprocessing tool. The thermometric technique of temperature-dependent phase changes in gradient-recalled echo pulse sequences are commonly used to determine the temperature change [156]. The change in temperature is represented as

$$
\Delta \mathrm{T}=\frac{\Delta \phi}{\gamma \cdot c \cdot B_{0} \cdot T E}
$$

where $\Delta \phi$ is the phase change, $\gamma$ is the gyromagnetic ratio, $\mathrm{c}$ is the proton-resonance frequency shift constant $(-0.01$ $\mathrm{ppm} /{ }^{\circ} \mathrm{C}$ ) [157], $\mathrm{B}_{\mathrm{o}}$ is the main magnetic field strength, and TE is the echo time. For the bone tumors, the calcification issues can be resolved be using susceptibility-weighted MRI to identify calcifications rather than computer tomography. An ultrashort TE sequence can be used to improve thermometry in bone.

\section{2) Clinical applications}

Clinical applications of MRgFUS are still limited. MRgFUS has been used in clinical studies in patients with uterine fibroids [158], bone metastases [159], prostate cancer [160], breast cancer [161], and brain diseases, such as brain tumors [162], intractable essential tremor [163], Parkinson's disease [164], obsessive-compulsive disorder [165], major depressive disorders [166], and neuropathic pain [167].

\section{MRI-guided linear accelerator}

MRI-guided linear accelerator (MRI-LINAC) is a recently developed and advanced radiation treatment system. As indicating the name, the MRI-LINAC is fully integrated with the MRI for imaging soft-tissue tumors together with LINAC for the radiotherapy to treat cancers throughout the body. The advantage of MRI-based imaging on a linear accelerator has superior high-definition image quality, especially for some soft-tissue cancers compared with CT-based imaging in the traditional linear accelerators to visualize the target area and adjacent anatomy for treatment setup and delivery. The first technical prototype MR-Linac was developed and installed in the University Medical Center Utrecht in Utrecht, The Netherlands. Similar types of measurements have been performed on a hybrid MRI Cobalt-60 device [168]. The first clinically active MRI-guided radiation therapy machine (ViewRay) was installed at the Alvin J. Siteman Cancer Center at Barnes-Jewish Hospital at the Washington University School of Medicine (St. Louis, MO, USA). The treatment of the first patients was announced in February 2014.

\section{1) Technical developments}

LINAC is affected by MRI. Two main configurations of MRI-LINAC that are being pursued with the radiotherapy beam are either parallel or perpendicular to the main magnetic field. This configuration is affected by the interference between the delivery of the radiation beam of LINAC and MRI. The operation of the multileaf collimator in the strong magnetic field can be a problem in the shaping of the Xray beam [169]. Both configurations have this problem, and vendors lowered magnetic field to minimize this issue. Another issue in the MRI-LINAC is that the accelerated 
electrons used to produce the X-ray beam can be deviated or defocused, thus causing a loss of the beam current. Previous studies showed that the perpendicular configuration is dominant to the total beam loss compared with the parallel one $[170,171]$. Skin dose can be increased by secondary electrons owing to the influence of the magnetic field [172]. In this case, the perpendicular configuration should be advantageous, although the electron return effect can still appear [173]. Receiver coils can cause attenuation of the primary beam and can increase the skin dose. Detailed explanation can be found in another paper [174].

MRI quality is also affected by the LINAC. Any RF noise generated by the LINAC can cause artifacts or noise in images. In addition, LINAC components, such as the accelerator or multileaf collimators cause inhomogeneity of the main magnetic field, thus worsening the imaging quality [175]. Finally, the radiation beam can affect conductors or electronics in the coil, causing imaging artifacts $[176,177]$.

\section{2) Clinical applications}

The MRI-LINAC can adapt the radiation treatment plan based on movement of the organs or tumor, and also track the motion of the tumor. This system reduces complications after radiation treatments. The MRI-LINAC can be used to improve the personalization of the radiation therapy using existing contrast imaging mechanisms, such as diffusion, perfusion, functional, and metabolic, to evaluate treatment effects. The hybrid system has been focused on daily plan changes based on geometric changes in the organs-at-risk $[178,179]$. Furthermore, MRI has been used to evaluate radiation treatment effects [180]. Currently, this hybrid system is used to treat patients with prostate cancer [181], pelvic lymph nodes [182], and the esophagus [183].

\section{Acknowledgements}

The research was supported by the National Research Foundation of Korea grant funded by Ministry of Science and ICT (No. 2020R1A2C1004749, GHJ), Republic of Korea.

\section{Conflicts of Interest}

The authors have nothing to disclose.

\section{Availability of Data and Materials}

The authors confirm that the data supporting the findings of this study are available within the article.

\section{Author Contributions}

Conceptualization: Geon-Ho Jahng. Data curation: GeonHo Jahng, Soonchan Park, Chang-Woo Ryu, and Zang-Hee Cho. Writing-original drafting: Geon-Ho Jahng. Writingreview \& editing: Geon-Ho Jahng, Soonchan Park, ChangWoo Ryu, and Zang-Hee Cho.

\section{References}

1. Jackson JA, Langham WH. Whole-body NMR spectrometer. Rev Sci Instrum. 1968;39:510-513.

2. Damadian R. Tumor detection by nuclear magnetic resonance. Science. 1971;171:1151-1153.

3. Lauterbur PC. Image formation by induced local interactions. Examples employing nuclear magnetic resonance. 1973. Clin Orthop Relat Res. 1989;(244):3-6.

4. Lauterbur PC. Magnetic resonance zeugmatography. Pure Appl Chem. 1974;40:149-157.

5. Mansfield P, Grannell P. "Diffraction" and microscopy in solids and liquids by NMR. Phys Rev B. 1975;12:3618.

6. Damadian R, Minkoff L, Goldsmith M, Stanford M, Koutcher J. Field focusing nuclear magnetic resonance (FONAR): visualization of a tumor in a live animal. Science. 1976;194:1430-1432.

7. Cho ZH, Kim YB, Han JY, Kim NB, Hwang SI, Kim SJ, et al. Altered $\mathrm{T}^{*}$ relaxation time of the hippocampus in major depressive disorder: implications of ultra-high field magnetic resonance imaging. J Psychiatr Res. 2010;44:881-886.

8. Cho ZH, Lee YB, Kang CK, Yang JW, Jung IH, Park CA, et al. Microvascular imaging of asymptomatic MCA stenoocclusive patients using ultra-high-field 7T MRI. J Neurol. 2013;260:144-150.

9. Cho ZH, Son YD, Kim HK, Kim KN, Oh SH, Han JY, et al. A fusion PET-MRI system with a high-resolution research tomograph-PET and ultra-high field 7.0 T-MRI for the molecular-genetic imaging of the brain. Proteomics. 2008;8: 1302-1323. 
10. Kim M, Kim KE, Jeong SW, Hwang SW, Jo H, Lee J, et al. Effects of the ultra-high-frequency electrical field radiofrequency device on mouse skin: a histologic and molecular study. Plast Reconstr Surg. 2016;138:248e-255e.

11. Oh SH, Chung JY, In MH, Zaitsev M, Kim YB, Speck O, et al. Distortion correction in EPI at ultra-high-field MRI using PSF mapping with optimal combination of shift detection dimension. Magn Reson Med. 2012;68:1239-1246.

12. Richards K, Calamante F, Tournier JD, Kurniawan ND, Sadeghian F, Retchford AR, et al. Mapping somatosensory connectivity in adult mice using diffusion MRI tractography and super-resolution track density imaging. Neuroimage. 2014;102 Pt 2:381-392.

13. Hahn EL. Spin echoes. Phys Rev. 1950;80:580.

14. Hahn EL. Nuclear induction due to free larmor precession. Phys Rev. 1950;77:297.

15. Hajnal JV, De Coene B, Lewis PD, Baudouin CJ, Cowan FM, Pennock JM, et al. High signal regions in normal white matter shown by heavily T2-weighted CSF nulled IR sequences. J Comput Assist Tomogr. 1992;16:506-513.

16. Ogawa S, Lee TM, Kay AR, Tank DW. Brain magnetic resonance imaging with contrast dependent on blood oxygenation. Proc Natl Acad Sci U S A. 1990;87:9868-9872.

17. Reichenbach JR, Venkatesan R, Schillinger DJ, Kido DK, Haacke EM. Small vessels in the human brain: MR venography with deoxyhemoglobin as an intrinsic contrast agent. Radiology. 1997;204:272-277.

18. Hennig J, Nauerth A, Friedburg H. RARE imaging: a fast imaging method for clinical MR. Magn Reson Med. 1986; 3:823-833.

19. Ahn CB, Kim JH, Cho ZH. High-speed spiral-scan echo planar NMR imaging-I. IEEE Trans Med Imaging. 1986;5: 2-7.

20. Meyer CH, Hu BS, Nishimura DG, Macovski A. Fast spiral coronary artery imaging. Magn Reson Med. 1992;28:202213.

21. Hennig J, Friedburg H. Clinical applications and methodological developments of the RARE technique. Magn Reson Imaging. 1988;6:391-395.

22. Kiefer B, Grassner J, I-lausman K. Image acquisition in a second with half fourier acquisition single shot turbo spin echo. J Magn Reson Imaging. 1994;4(P):86.

23. Oshio K, Feinberg DA. GRASE (Gradient- and spin-echo) imaging: a novel fast MRI technique. Magn Reson Med. 1991;20:344-349.

24. Nayak KS, Hargreaves BA, Hu BS, Nishimura DG, Pauly JM, Meyer CH. Spiral balanced steady-state free precession cardiac imaging. Magn Reson Med. 2005;53:14681473.

25. Mansfield P. Multi-planar image formation using NMR spin echoes. J Phys C. 1977;10:L55.

26. Du J, Lu A, Block WF, Thornton FJ, Grist TM, Mistretta CA. Time-resolved undersampled projection reconstruction magnetic resonance imaging of the peripheral vessels using multi-echo acquisition. Magn Reson Med. 2005;53: 730-734.

27. Sodickson DK, Manning WJ. Simultaneous acquisition of spatial harmonics (SMASH): fast imaging with radiofrequency coil arrays. Magn Reson Med. 1997;38:591-603.

28. Pruessmann KP, Weiger M, Scheidegger MB, Boesiger P. SENSE: sensitivity encoding for fast MRI. Magn Reson Med. 1999;42:952-962.

29. Griswold MA, Jakob PM, Heidemann RM, Nittka M, Jellus V, Wang J, et al. Generalized autocalibrating partially parallel acquisitions (GRAPPA). Magn Reson Med. 2002;47: 1202-1210.

30. Hamilton J, Franson D, Seiberlich N. Recent advances in parallel imaging for MRI. Prog Nucl Magn Reson Spectrosc. 2017;101:71-95.

31. Feinberg DA, Setsompop K. Ultra-fast MRI of the human brain with simultaneous multi-slice imaging. J Magn Reson. 2013;229:90-100.

32. Larkman DJ, Hajnal JV, Herlihy AH, Coutts GA, Young IR, Ehnholm G. Use of multicoil arrays for separation of signal from multiple slices simultaneously excited. J Magn Reson Imaging. 2001;13:313-317.

33. Feinberg DA, Reese TG, Wedeen VJ. Simultaneous echo refocusing in EPI. Magn Reson Med. 2002;48:1-5.

34. Panda A, Mehta BB, Coppo S, Jiang Y, Ma D, Seiberlich N, et al. Magnetic resonance fingerprinting-an overview. Curr Opin Biomed Eng. 2017;3:56-66.

35. Ma D, Gulani V, Seiberlich N, Liu K, Sunshine JL, Duerk JL, et al. Magnetic resonance fingerprinting. Nature. 2013;495:187-192.

36. Tsao J. Ultrafast imaging: principles, pitfalls, solutions, and applications. J Magn Reson Imaging. 2010;32:252-266. 
37. Saini S, Stark DD, Rzedzian RR, Pykett IL, Rummeny E, Hahn PF, et al. Forty-millisecond MR imaging of the abdomen at 2.0 T. Radiology. 1989;173:111-116.

38. Doyle M, Rzedzian R, Mansfield P, Coupland RE. Dynamic NMR cardiac imaging in a piglet. Br J Radiol. 1983;56: 925-930.

39. Glover GH, Lee AT. Motion artifacts in fMRI: comparison of 2DFT with PR and spiral scan methods. Magn Reson Med. 1995;33:624-635.

40. Muthurangu V, Lurz P, Critchely JD, Deanfield JE, Taylor AM, Hansen MS. Real-time assessment of right and left ventricular volumes and function in patients with congenital heart disease by using high spatiotemporal resolution radial k-t SENSE. Radiology. 2008;248:782-791.

41. Nayak KS, Cunningham CH, Santos JM, Pauly JM. Realtime cardiac MRI at 3 tesla. Magn Reson Med. 2004;51: 655-660.

42. Yu AC, Badve C, Ponsky LE, Pahwa S, Dastmalchian S, Rogers M, et al. Development of a combined MR fingerprinting and diffusion examination for prostate cancer. Radiology. 2017;283:729-738.

43. Cloos MA, Knoll F, Zhao T, Block KT, Bruno M, Wiggins GC, et al. Multiparametric imaging with heterogeneous radiofrequency fields. Nat Commun. 2016;7:12445.

44. Hamilton JI, Jiang Y, Chen Y, Ma D, Lo WC, Griswold M, et al. MR fingerprinting for rapid quantification of myocardial $\mathrm{T}_{1}, \mathrm{~T}_{2}$, and proton spin density. Magn Reson Med. 2017;77:1446-1458.

45. Su P, Mao D, Liu P, Li Y, Pinho MC, Welch BG, et al. Multiparametric estimation of brain hemodynamics with MR fingerprinting ASL. Magn Reson Med. 2017;78:1812-1823.

46. Christen T, Pannetier NA, Ni WW, Qiu D, Moseley ME, Schuff N, et al. MR vascular fingerprinting: a new approach to compute cerebral blood volume, mean vessel radius, and oxygenation maps in the human brain. Neuroimage. 2014;89:262-270.

47. Einstein A. Investigations on the theory of the Brownian movement. Chelmsford: Courier Corporation; 1956.

48. Le Bihan D, Breton E, inventor; General Electric CGR SA, assignee. Method to measure the molecular diffusion and/or perfusion parameters of live tissue. United States patent US4809701A. 1989 Mar 7.

49. Howe FA, Filler AG, Bell BA, Griffiths JR. Magnetic reso- nance neurography. Magn Reson Med. 1992;28:328-338.

50. Le Bihan D, Breton E, Lallemand D, Grenier P, Cabanis E, Laval-Jeantet M. MR imaging of intravoxel incoherent motions: application to diffusion and perfusion in neurologic disorders. Radiology. 1986;161:401-407.

51. Basser PJ, Mattiello J, LeBihan D. Estimation of the effective self-diffusion tensor from the NMR spin echo. J Magn Reson B. 1994;103:247-254.

52. Niendorf T, Dijkhuizen RM, Norris DG, van Lookeren Campagne M, Nicolay K. Biexponential diffusion attenuation in various states of brain tissue: implications for diffusion-weighted imaging. Magn Reson Med. 1996;36:847857.

53. Assaf Y, Freidlin RZ, Rohde GK, Basser PJ. New modeling and experimental framework to characterize hindered and restricted water diffusion in brain white matter. Magn Reson Med. 2004;52:965-978.

54. Behrens TE, Woolrich MW, Jenkinson M, Johansen-Berg H, Nunes RG, Clare S, et al. Characterization and propagation of uncertainty in diffusion-weighted MR imaging. Magn Reson Med. 2003;50:1077-1088.

55. Tuch DS. Q-ball imaging. Magn Reson Med. 2004;52:13581372.

56. Wedeen VJ, Wang RP, Schmahmann JD, Benner T, Tseng WY, Dai G, et al. Diffusion spectrum magnetic resonance imaging (DSI) tractography of crossing fibers. Neuroimage. 2008;41:1267-1277.

57. Tournier JD, Calamante F, Gadian DG, Connelly A. Direct estimation of the fiber orientation density function from diffusion-weighted MRI data using spherical deconvolution. Neuroimage. 2004;23:1176-1185.

58. Zhang H, Schneider T, Wheeler-Kingshott CA, Alexander DC. NODDI: practical in vivo neurite orientation dispersion and density imaging of the human brain. Neuroimage. 2012;61:1000-1016.

59. Jensen JH, Helpern JA, Ramani A, Lu H, Kaczynski K. Diffusional kurtosis imaging: the quantification of nongaussian water diffusion by means of magnetic resonance imaging. Magn Reson Med. 2005;53:1432-1440.

60. Basser PJ, Pajevic S, Pierpaoli C, Duda J, Aldroubi A. In vivo fiber tractography using DT-MRI data. Magn Reson Med. 2000;44:625-632.

61. Mori S, Crain BJ, Chacko VP, van Zijl PC. Three-dimen- 
sional tracking of axonal projections in the brain by magnetic resonance imaging. Ann Neurol. 1999;45:265-269.

62. Jones DK. Tractography gone wild: probabilistic fibre tracking using the wild bootstrap with diffusion tensor MRI. IEEE Trans Med Imaging. 2008;27:1268-1274.

63. Bullmore E, Sporns O. Complex brain networks: graph theoretical analysis of structural and functional systems. Nat Rev Neurosci. 2009;10:186-198.

64. Sotak $\mathrm{CH}$. The role of diffusion tensor imaging in the evaluation of ischemic brain injury - a review. NMR Biomed. 2002;15:561-569.

65. Alexander AL, Hurley SA, Samsonov AA, Adluru N, Hosseinbor AP, Mossahebi P, et al. Characterization of cerebral white matter properties using quantitative magnetic resonance imaging stains. Brain Connect. 2011;1:423-446.

66. Baliyan V, Das CJ, Sharma R, Gupta AK. Diffusion weighted imaging: technique and applications. World J Radiol. 2016;8:785-798.

67. Zhang Y, Schuff N, Jahng GH, Bayne W, Mori S, Schad L, et al. Diffusion tensor imaging of cingulum fibers in mild cognitive impairment and Alzheimer disease. Neurology. 2007;68:13-19.

68. Zhang Y, Du AT, Hayasaka S, Jahng GH, Hlavin J, Zhan W, et al. Patterns of age-related water diffusion changes in human brain by concordance and discordance analysis. Neurobiol Aging. 2010;31:1991-2001.

69. Jahng GH, Xu S, Weiner MW, Meyerhoff DJ, Park S, Schuff N. DTI studies in patients with Alzheimer's disease, mild cognitive impairment, or normal cognition with evaluation of the intrinsic background gradients. Neuroradiology. 2011;53:749-762.

70. Jahng GH, Xu S. Local susceptibility causes diffusion alterations in patients with Alzheimer's disease and mild cognitive impairment. Brain Imaging Behav. 2012;6:426436.

71. Jahng GH, Xu S, Kim MJ. Mapping of distributions of a local b-matrix cross-term strength using diffusion tensor MRI in patients with Alzheimer's disease. Med Phys. 2012; 39:6324-6331.

72. Charles-Edwards EM, deSouza NM. Diffusion-weighted magnetic resonance imaging and its application to cancer. Cancer Imaging. 2006;6:135-143.

73. Takahara T, Imai Y, Yamashita T, Yasuda S, Nasu S, Van
Cauteren M. Diffusion weighted whole body imaging with background body signal suppression (DWIBS): technical improvement using free breathing, STIR and high resolution 3D display. Radiat Med. 2004;22:275-282.

74. Larsen EH. [August Krogh (1874-1949): 1920 nobel prize]. Ugeskr Laeger. 2007;169:2878. Danish.

75. Villringer A, Rosen BR, Belliveau JW, Ackerman JL, Lauffer RB, Buxton RB, et al. Dynamic imaging with lanthanide chelates in normal brain: contrast due to magnetic susceptibility effects. Magn Reson Med. 1988;6:164174.

76. Koretsky AP. Early development of arterial spin labeling to measure regional brain blood flow by MRI. Neuroimage. 2012;62:602-607.

77. Jahng GH, Li KL, Ostergaard L, Calamante F. Perfusion magnetic resonance imaging: a comprehensive update on principles and techniques. Korean J Radiol. 2014;15:554577.

78. Ostergaard L, Weisskoff RM, Chesler DA, Gyldensted C, Rosen BR. High resolution measurement of cerebral blood flow using intravascular tracer bolus passages. Part I: Mathematical approach and statistical analysis. Magn Reson Med. 1996;36:715-725.

79. Tofts PS. Modeling tracer kinetics in dynamic Gd-DTPA MR imaging. J Magn Reson Imaging. 1997;7:91-101.

80. Buxton RB, Frank LR, Wong EC, Siewert B, Warach S, Edelman RR. A general kinetic model for quantitative perfusion imaging with arterial spin labeling. Magn Reson Med. 1998;40:383-396.

81. Dai W, Garcia D, de Bazelaire C, Alsop DC. Continuous flow-driven inversion for arterial spin labeling using pulsed radio frequency and gradient fields. Magn Reson Med. 2008;60:1488-1497.

82. Keir SL, Wardlaw JM. Systematic review of diffusion and perfusion imaging in acute ischemic stroke. Stroke. 2000; 31:2723-2731.

83. Cha S, Knopp EA, Johnson G, Wetzel SG, Litt AW, Zagzag D. Intracranial mass lesions: dynamic contrast-enhanced susceptibility-weighted echo-planar perfusion MR imaging. Radiology. 2002;223:11-29.

84. Ostergaard L, Sorensen AG, Chesler DA, Weisskoff RM, Koroshetz WJ, Wu O, et al. Combined diffusion-weighted and perfusion-weighted flow heterogeneity magnetic 
resonance imaging in acute stroke. Stroke. 2000;31:10971103.

85. Lee SJ, Kim JH, Kim YM, Lee GK, Lee EJ, Park IS, et al. Perfusion MR imaging in gliomas: comparison with histologic tumor grade. Korean J Radiol. 2001;2:1-7.

86. Brix G, Kiessling F, Lucht R, Darai S, Wasser K, Delorme $\mathrm{S}$, et al. Microcirculation and microvasculature in breast tumors: pharmacokinetic analysis of dynamic MR image series. Magn Reson Med. 2004;52:420-429.

87. Choi HS, Kim AH, Ahn SS, Shin NY, Kim J, Lee SK. Glioma grading capability: comparisons among parameters from dynamic contrast-enhanced MRI and ADC value on DWI. Korean J Radiol. 2013;14:487-492.

88. Ahn SS, Shin NY, Chang JH, Kim SH, Kim EH, Kim DW, et al. Prediction of methylguanine methyltransferase promoter methylation in glioblastoma using dynamic contrast-enhanced magnetic resonance and diffusion tensor imaging. J Neurosurg. 2014;121:367-373.

89. Suh CH, Kim HS, Choi YJ, Kim N, Kim SJ. Prediction of pseudoprogression in patients with glioblastomas using the initial and final area under the curves ratio derived from dynamic contrast-enhanced T1-weighted perfusion MR imaging. AJNR Am J Neuroradiol. 2013;34:2278-2286.

90. Kim SM, Kim MJ, Rhee HY, Ryu CW, Kim EJ, Petersen ET, et al. Regional cerebral perfusion in patients with Alzheimer's disease and mild cognitive impairment: effect of APOE epsilon4 allele. Neuroradiology. 2013;55:25-34.

91. Johnson NA, Jahng GH, Weiner MW, Miller BL, Chui HC, Jagust WJ, et al. Pattern of cerebral hypoperfusion in Alzheimer disease and mild cognitive impairment measured with arterial spin-labeling MR imaging: initial experience. Radiology. 2005;234:851-859.

92. Choi YJ, Kim HS, Jahng GH, Kim SJ, Suh DC. Pseudoprogression in patients with glioblastoma: added value of arterial spin labeling to dynamic susceptibility contrast perfusion MR imaging. Acta Radiol. 2013;54:448-454.

93. Wang J, Licht DJ, Jahng GH, Liu CS, Rubin JT, Haselgrove J, et al. Pediatric perfusion imaging using pulsed arterial spin labeling. J Magn Reson Imaging. 2003;18:404-413.

94. Bottomley PA. Spatial localization in NMR spectroscopy in vivo. Ann N Y Acad Sci. 1987;508:333-348.

95. Frahm J, Bruhn H, Gyngell ML, Merboldt KD, Hänicke W, Sauter R. Localized high-resolution proton NMR spec- troscopy using stimulated echoes: initial applications to human brain in vivo. Magn Reson Med. 1989;9:79-93.

96. Ordidge RJ, Connelly A, Lohman JA. Image-selected in vivo spectroscopy (ISIS). A new technique for spatially selective NMR spectroscopy. J Magn Reson (1969). 1986;66: 283-294.

97. Bottomley PA, Foster TB, Darrow RD. Depth-resolved surface-coil spectroscopy (DRESS) for in vivo ${ }^{1} \mathrm{H},{ }^{31} \mathrm{P}$, and ${ }^{13}$ C NMR. J Magn Reson (1969). 1984;59:338-342.

98. Thrippleton MJ, Edden RA, Keeler J. Suppression of strong coupling artefacts in J-spectra. J Magn Reson. 2005;174:97109.

99. Gruber S, Pinker K, Riederer F, Chmelík M, Stadlbauer A, Bittsanský M, et al. Metabolic changes in the normal ageing brain: consistent findings from short and long echo time proton spectroscopy. Eur J Radiol. 2008;68:320-327.

100. Skoch A, Jiru F, Bunke J. Spectroscopic imaging: basic principles. Eur J Radiol. 2008;67:230-239.

101. Haase A, Frahm J, Hänicke W, Matthaei D. 1H NMR chemical shift selective (CHESS) imaging. Phys Med Biol. 1985;30:341-344.

102. Maudsley AA, Domenig C, Govind V, Darkazanli A, Studholme C, Arheart K, et al. Mapping of brain metabolite distributions by volumetric proton MR spectroscopic imaging (MRSI). Magn Reson Med. 2009;61:548-559.

103. Provencher SW. Estimation of metabolite concentrations from localized in vivo proton NMR spectra. Magn Reson Med. 1993;30:672-679.

104. Provencher SW. Automatic quantitation of localized in vivo $1 \mathrm{H}$ spectra with LCModel. NMR Biomed. 2001;14:260264.

105. Reynolds G, Wilson M, Peet A, Arvanitis TN. An algorithm for the automated quantitation of metabolites in in vitro NMR signals. Magn Reson Med. 2006;56:1211-1219.

106. Naressi A, Couturier C, Castang I, de Beer R, GraveronDemilly D. Java-based graphical user interface for MRUI, a software package for quantitation of in vivo/medical magnetic resonance spectroscopy signals. Comput Biol Med. 2001;31:269-286.

107. Naressi A, Couturier C, Devos JM, Janssen M, Mangeat C, de Beer R, et al. Java-based graphical user interface for the MRUI quantitation package. MAGMA. 2001;12:141-152.

108. van Zijl PC, Yadav NN. Chemical exchange saturation 
transfer (CEST): what is in a name and what isn't? Magn Reson Med. 2011;65:927-948.

109. Vinogradov E, Sherry AD, Lenkinski RE. CEST: from basic principles to applications, challenges and opportunities. J Magn Reson. 2013;229:155-172.

110. Park JE, Jahng GH, Jeong HK. Amide proton transfer imaging in clinics: basic concepts and current and future use in brain tumors and stroke. J Korean Soc Radiol. 2016;75:419-433.

111. Jahng GH, Oh JH. Physical modeling of chemical exchange saturation transfer imaging. Prog Med Phys. 2017; 28:135-143.

112. Oh JH, Kim HG, Woo DC, Jeong HK, Lee SY, Jahng GH. Chemical-exchange-saturation-transfer magnetic resonance imaging to map gamma-aminobutyric acid, glutamate, myoinositol, glycine, and asparagine: phantom experiments. J Korean Phys Soc. 2017;70:545-553.

113. Jahng GH, Choi W, Chung JJ, Kim ST, Rhee HY. Mapping exchangeable protons to monitor protein alterations in the brain of an Alzheimer's disease mouse model by using MRI. Curr Alzheimer Res. 2018;15:1343-1353.

114. Yoo CH, Oh J, Park S, Ryu CW, Kwon YK, Jahng GH. Comparative evaluation of the polynomial and spline fitting methods for the B0 correction of CEST MRI data acquired from human brains. Int J Imaging Syst Technol. 2019;29: 272-282.

115. Oh JH, Kim HG, Woo DC, Rhee SJ, Lee SY, Jahng GH. Preliminary phantom experiments to map amino acids and neurotransmitters using MRI. Prog Med Phys. 2018;29:2941.

116. Park S, Jang J, Oh JH, Ryu CW, Jahng GH. Assessment of the cerebrospinal fluid effect on the chemical exchange saturation transfer map obtained from the full Z-spectrum in the elderly human brain. Prog Med Phys. 2019;30: 139-149.

117. Bruhn H, Frahm J, Gyngell ML, Merboldt KD, Hänicke W, Sauter R. Cerebral metabolism in man after acute stroke: new observations using localized proton NMR spectroscopy. Magn Reson Med. 1989;9:126-131.

118. Arnold DL, Matthews PM, Francis G, Antel J. Proton magnetic resonance spectroscopy of human brain in vivo in the evaluation of multiple sclerosis: assessment of the load of disease. Magn Reson Med. 1990;14:154-159.
119. Miller BL, Moats RA, Shonk T, Ernst T, Woolley S, Ross BD. Alzheimer disease: depiction of increased cerebral myoinositol with proton MR spectroscopy. Radiology. 1993; 187:433-437.

120. Jahng GH, Oh J, Lee DW, Kim HG, Rhee HY, Shin W, et al. Glutamine and glutamate complex, as measured by functional magnetic resonance spectroscopy, alters during face-name association task in patients with mild cognitive impairment and Alzheimer's disease. J Alzheimers Dis. 2016;52:145-159.

121. Bruhn H, Frahm J, Gyngell ML, Merboldt KD, Hänicke W, Sauter R, et al. Noninvasive differentiation of tumors with use of localized H-1 MR spectroscopy in vivo: initial experience in patients with cerebral tumors. Radiology. 1989; 172:541-548.

122. Sciarra A, Panebianco V, Ciccariello M, Salciccia S, Cattarino S, Lisi D, et al. Value of magnetic resonance spectroscopy imaging and dynamic contrast-enhanced imaging for detecting prostate cancer foci in men with prior negative biopsy. Clin Cancer Res. 2010;16:1875-1883.

123. Haddadin IS, McIntosh A, Meisamy S, Corum C, Styczynski Snyder AL, Powell NJ, et al. Metabolite quantification and high-field MRS in breast cancer. NMR Biomed. 2009; 22:65-76.

124. Zhao X, Wen Z, Zhang G, Huang F, Lu S, Wang X, et al. Three-dimensional turbo-spin-echo amide proton transfer MR imaging at 3-Tesla and its application to highgrade human brain tumors. Mol Imaging Biol. 2013;15:114122.

125. Zhou J, Tryggestad E, Wen Z, Lal B, Zhou T, Grossman R, et al. Differentiation between glioma and radiation necrosis using molecular magnetic resonance imaging of endogenous proteins and peptides. Nat Med. 2011;17:130134.

126. Wang M, Hong X, Chang CF, Li Q, Ma B, Zhang H, et al. Simultaneous detection and separation of hyperacute intracerebral hemorrhage and cerebral ischemia using amide proton transfer MRI. Magn Reson Med. 2015;74:4250.

127. Dula AN, Arlinghaus LR, Dortch RD, Dewey BE, Whisenant JG, Ayers GD, et al. Amide proton transfer imaging of the breast at $3 \mathrm{~T}$ : establishing reproducibility and possible feasibility assessing chemotherapy response. 
Magn Reson Med. 2013;70:216-224.

128. Jia G, Abaza R, Williams JD, Zynger DL, Zhou J, Shah ZK, et al. Amide proton transfer MR imaging of prostate cancer: a preliminary study. J Magn Reson Imaging. 2011;33: 647-654.

129. Ling W, Regatte RR, Navon G, Jerschow A. Assessment of glycosaminoglycan concentration in vivo by chemical exchange-dependent saturation transfer (gagCEST). Proc Natl Acad Sci U S A. 2008;105:2266-2270.

130. Yamamoto S, Kuroda K, Senda M. Scintillator selection for MR-compatible gamma detectors. IEEE Trans Nucl Sci. 2003;50:1683-1685.

131. Pichler BJ, Judenhofer MS, Catana C, Walton JH, Kneilling M, Nutt RE, et al. Performance test of an LSO-APD detector in a 7-T MRI scanner for simultaneous PET/MRI. J Nucl Med. 2006;47:639-647.

132. Kinahan PE, Townsend DW, Beyer T, Sashin D. Attenuation correction for a combined 3D PET/CT scanner. Med Phys. 1998;25:2046-2053.

133. Wagenknecht G, Kaiser HJ, Mottaghy FM, Herzog H. MRI for attenuation correction in PET: methods and challenges. MAGMA. 2013;26:99-113.

134. Schulz V, Torres-Espallardo I, Renisch S, Hu Z, Ojha N, Börnert P, et al. Automatic, three-segment, MR-based attenuation correction for whole-body PET/MR data. Eur J Nucl Med Mol Imaging. 2011;38:138-152.

135. Beyer T, Lassen ML, Boellaard R, Delso G, Yaqub M, Sattler B, et al. Investigating the state-of-the-art in wholebody MR-based attenuation correction: an intra-individual, inter-system, inventory study on three clinical PET/ MR systems. MAGMA. 2016;29:75-87.

136. Martinez-Möller A, Souvatzoglou M, Delso G, Bundschuh RA, Chefd'hotel C, Ziegler SI, et al. Tissue classification as a potential approach for attenuation correction in wholebody PET/MRI: evaluation with PET/CT data. J Nucl Med. 2009;50:520-526.

137. Nuyts J, Dupont P, Stroobants S, Benninck R, Mortelmans L, Suetens P. Simultaneous maximum a posteriori reconstruction of attenuation and activity distributions from emission sinograms. IEEE Trans Med Imaging. 1999;18:393-403.

138. Johansson A, Karlsson M, Nyholm T. CT substitute derived from MRI sequences with ultrashort echo time. Med
Phys. 2011;38:2708-2714.

139. King AP, Buerger C, Tsoumpas C, Marsden PK, Schaeffter T. Thoracic respiratory motion estimation from MRI using a statistical model and a 2-D image navigator. Med Image Anal. 2012;16:252-264.

140. Uribe S, Muthurangu V, Boubertakh R, Schaeffter T, Razavi R, Hill DL, et al. Whole-heart cine MRI using real-time respiratory self-gating. Magn Reson Med. 2007;57:606613.

141. Erlandsson K, Dickson J, Arridge S, Atkinson D, Ourselin S, Hutton BF. MR Imaging-guided partial volume correction of PET data in PET/MR imaging. PET Clin. 2016;11:161-177.

142. Bai B, Li Q, Leahy RM. Magnetic resonance-guided positron emission tomography image reconstruction. Semin Nucl Med. 2013;43:30-44.

143. Wahl RL, Quint LE, Cieslak RD, Aisen AM, Koeppe RA, Meyer CR. "Anatometabolic" tumor imaging: fusion of FDG PET with CT or MRI to localize foci of increased activity. J Nucl Med. 1993;34:1190-1197.

144. Kirchner J, Sawicki LM, Deuschl C, Grüneisen J, Beiderwellen K, Lauenstein TC, et al. 18 F-FDG PET/MR imaging in patients with suspected liver lesions: value of liverspecific contrast agent Gadobenate dimeglumine. PLoS One. 2017;12:e0180349.

145. Baumann T, Rottenburger C, Nicolas G, Wild D. Gastroenteropancreatic neuroendocrine tumours (GEP-NET) - Imaging and staging. Best Pract Res Clin Endocrinol Metab. 2016;30:45-57.

146. Chen BB, Tien YW, Chang MC, Cheng MF, Chang YT, Wu $\mathrm{CH}$, et al. PET/MRI in pancreatic and periampullary cancer: correlating diffusion-weighted imaging, MR spectroscopy and glucose metabolic activity with clinical stage and prognosis. Eur J Nucl Med Mol Imaging. 2016;43:17531764.

147. Eiber M, Weirich G, Holzapfel K, Souvatzoglou M, Haller B, Rauscher I, et al. Simultaneous ${ }^{68}$ Ga-PSMA HBED-CC PET/MRI improves the localization of primary prostate cancer. Eur Urol. 2016;70:829-836.

148. Miller-Thomas MM, Benzinger TL. Neurologic applications of PET/MR imaging. Magn Reson Imaging Clin N Am. 2017;25:297-313.

149. Jack CR Jr, Albert MS, Knopman DS, McKhann GM, Sperling RA, Carrillo MC, et al. Introduction to the recommen- 
dations from the National Institute on Aging-Alzheimer's Association workgroups on diagnostic guidelines for Alzheimer's disease. Alzheimers Dement. 2011;7:257-262.

150. Lee KK, Salamon N. $\left[{ }^{18} \mathrm{~F}\right]$ fluorodeoxyglucose-positronemission tomography and MR imaging coregistration for presurgical evaluation of medically refractory epilepsy. AJNR Am J Neuroradiol. 2009;30:1811-1816.

151. Kransdorf MJ, Bridges MD. Current developments and recent advances in musculoskeletal tumor imaging. Semin Musculoskelet Radiol. 2013;17:145-155.

152. Abgral R, Dweck MR, Trivieri MG, Robson PM, Karakatsanis N, Mani V, et al. Clinical utility of combined FDGPET/MR to assess myocardial disease. JACC Cardiovasc Imaging. 2017;10:594-597.

153. Dubinsky TJ, Cuevas C, Dighe MK, Kolokythas O, Hwang JH. High-intensity focused ultrasound: current potential and oncologic applications. AJR Am J Roentgenol. 2008; 190:191-199.

154. Cline HE, Schenck JF, Hynynen K, Watkins RD, Souza SP, Jolesz FA. MR-guided focused ultrasound surgery. J Comput Assist Tomogr. 1992;16:956-965.

155. Hynynen K, Darkazanli A, Unger E, Schenck JF. MRIguided noninvasive ultrasound surgery. Med Phys. 1993; 20:107-115.

156. Ishihara Y, Calderon A, Watanabe H, Okamoto K, Suzuki Y, Kuroda K, et al. A precise and fast temperature mapping using water proton chemical shift. Magn Reson Med. 1995;34:814-823.

157. Rieke V, Butts Pauly K. MR thermometry. J Magn Reson Imaging. 2008;27:376-390.

158. Lénárd ZM, McDannold NJ, Fennessy FM, Stewart EA, Jolesz FA, Hynynen K, et al. Uterine leiomyomas: MR imaging-guided focused ultrasound surgery--imaging predictors of success. Radiology. 2008;249:187-194.

159. Gianfelice D, Gupta C, Kucharczyk W, Bret P, Havill D, Clemons M. Palliative treatment of painful bone metastases with MR imaging--guided focused ultrasound. Radiology. 2008;249:355-363.

160. Benedict SH, De Meerleer G, Orton CG, Stancanello J. Point/counterpoint. High intensity focused ultrasound may be superior to radiation therapy for the treatment of early stage prostate cancer. Med Phys. 2011;38:3909-3912.

161. Hynynen K, Pomeroy O, Smith DN, Huber PE, McDannold
NJ, Kettenbach J, et al. MR imaging-guided focused ultrasound surgery of fibroadenomas in the breast: a feasibility study. Radiology. 2001;219:176-185.

162. Park J, Aryal M, Vykhodtseva N, Zhang YZ, McDannold N. Evaluation of permeability, doxorubicin delivery, and drug retention in a rat brain tumor model after ultrasound-induced blood-tumor barrier disruption. J Control Release. 2017;250:77-85.

163. Lipsman N, Schwartz ML, Huang Y, Lee L, Sankar T, Chapman M, et al. MR-guided focused ultrasound thalamotomy for essential tremor: a proof-of-concept study. Lancet Neurol. 2013;12:462-468.

164. Magara A, Bühler R, Moser D, Kowalski M, Pourtehrani P, Jeanmonod D. First experience with MR-guided focused ultrasound in the treatment of Parkinson's disease. J Ther Ultrasound. 2014;2:11.

165. Jung HH, Kim SJ, Roh D, Chang JG, Chang WS, Kweon EJ, et al. Bilateral thermal capsulotomy with MR-guided focused ultrasound for patients with treatment-refractory obsessive-compulsive disorder: a proof-of-concept study. Mol Psychiatry. 2015;20:1205-1211.

166. Kim M, Kim CH, Jung HH, Kim SJ, Chang JW. Treatment of major depressive disorder via magnetic resonanceguided focused ultrasound surgery. Biol Psychiatry. 2018; 83:e17-e18.

167. Jeanmonod D, Werner B, Morel A, Michels L, Zadicario E, Schiff G, et al. Transcranial magnetic resonance imagingguided focused ultrasound: noninvasive central lateral thalamotomy for chronic neuropathic pain. Neurosurg Focus. 2012;32:E1.

168. Saenz DL, Yan Y, Christensen N, Henzler MA, Forrest LJ, Bayouth JE, et al. Characterization of a $0.35 \mathrm{~T}$ MR system for phantom image quality stability and in vivo assessment of motion quantification. J Appl Clin Med Phys. 2015;16:30-40.

169. Yun J, St Aubin J, Rathee S, Fallone BG. Brushed permanent magnet DC MLC motor operation in an external magnetic field. Med Phys. 2010;37:2131-2134.

170. St Aubin J, Steciw S, Fallone BG. Effect of transverse magnetic fields on a simulated in-line 6 MV linac. Phys Med Biol. 2010;55:4861-4869.

171. St Aubin J, Santos DM, Steciw S, Fallone BG. Effect of longitudinal magnetic fields on a simulated in-line $6 \mathrm{MV}$ 
linac. Med Phys. 2010;37:4916-4923.

172. Bielajew AF. The effect of strong longitudinal magnetic fields on dose deposition from electron and photon beams. Med Phys. 1993;20:1171-1179.

173. Raaijmakers AJ, Raaymakers BW, Lagendijk JJ. Integrating a MRI scanner with a $6 \mathrm{MV}$ radiotherapy accelerator: dose increase at tissue-air interfaces in a lateral magnetic field due to returning electrons. Phys Med Biol. 2005;50:13631376.

174. Liney GP, Whelan B, Oborn B, Barton M, Keall P. MRIlinear accelerator radiotherapy systems. Clin Oncol (R Coll Radiol). 2018;30:686-691.

175. Emmerich J, Laun FB, Pfaffenberger A, Schilling R, Denoix M, Maier F, et al. Technical note: on the size of susceptibility-induced MR image distortions in prostate and cervix in the context of MR-guided radiation therapy. Med Phys. 2018;45:1586-1593.

176. Liney GP, Dong B, Begg J, Vial P, Zhang K, Lee F, et al. Technical note: experimental results from a prototype high-field inline MRI-linac. Med Phys. 2016;43:5188.

177. Burke B, Wachowicz K, Fallone BG, Rathee S. Effect of radiation induced current on the quality of MR images in an integrated linac-MR system. Med Phys. 2012;39:6139-6147.

178. Palacios MA, Bohoudi O, Bruynzeel AME, van Sörsen de
Koste JR, Cobussen P, Slotman BJ, et al. Role of daily plan adaptation in MR-guided stereotactic ablative radiation therapy for adrenal metastases. Int J Radiat Oncol Biol Phys. 2018;102:426-433.

179. Kontaxis C, Bol GH, Lagendijk JJ, Raaymakers BW. A new methodology for inter- and intrafraction plan adaptation for the MR-linac. Phys Med Biol. 2015;60:7485-7497.

180. Rudra S, Jiang N, Rosenberg SA, Olsen JR, Roach MC, Wan $\mathrm{L}$, et al. Using adaptive magnetic resonance image-guided radiation therapy for treatment of inoperable pancreatic cancer. Cancer Med. 2019;8:2123-2132.

181. Murray J, Tree AC. Prostate cancer- advantages and disadvantages of MR-guided RT. Clin Transl Radiat Oncol. 2019;18:68-73.

182. Werensteijn-Honingh AM, Kroon PS, Winkel D, Aalbers EM, van Asselen B, Bol GH, et al. Feasibility of stereotactic radiotherapy using a $1.5 \mathrm{~T}$ MR-linac: multi-fraction treatment of pelvic lymph node oligometastases. Radiother Oncol. 2019;134:50-54.

183. Winkel D, Bol GH, Kroon PS, van Asselen B, Hackett SS, Werensteijn-Honingh AM, et al. Adaptive radiotherapy: The Elekta Unity MR-linac concept. Clin Transl Radiat Oncol. 2019;18:54-59. 